\title{
AQUISIÇÃO DE INGLÊS COMO LÍNGUA ADICIONAL ATRAVÉS DA MESCLAGEM CONCEPTUAL EM VIDEOGAMES DE RPG
}

\author{
ACQUISITION IN ENGLISH AS AN ADDITIONAL LANGUAGE THROUGH CONCEPTUAL \\ BLENDING IN RPG VIDEO GAMES
}

\author{
ADQUISICIÓN DE INGLÉS COMO LENGUA ADICIONAL MEDIANTE MEZCLA CONCEPTUAL EN \\ VIDEOJUEGOS RPG
}

Luciana Braga Carneiro Leão Junqueira ${ }^{1}$

\begin{abstract}
RESUMO
O presente texto é um resumo da tese que objetivou analisar o conhecimento lexical em inglês como língua adicional desenvolvido através da formação e expansão de modelos cognitivos idealizados e frames na mente de jogadores durante a leitura extensiva propiciada por jogos de videogame de RPG. Como resultados, foram apresentadas propostas de representação dos modelos cognitivos idealizados e frames (FAUCONNIER, 1994) desenvolvidos pelos participantes durante o processamento cognitivo do vocabulário em inglês apresentado durante a fase jogada, bem como discussões sobre os processos que levaram aos seus desenvolvimentos, em especial as estratégias de aprendizagem (OXFORD, 1999; 2017; CARDOSO, 2016) empregadas pelos participantes, a mesclagem conceptual (FAUCONNIER, 1997) entre modelos cognitivos idealizados em língua materna e em inglês como língua adicional durante o jogo, e o grau de contribuição da multimodalidade (KREES; VAN LEEUWEN, 1996; HEMAIS, 2015) na mesclagem conceptual desses modelos cognitivos idealizados. A premissa da presente pesquisa era a de que a redundância de informações provida pela multimodalidade presente nos jogos de videogame de RPG permitiria a formulação de hipóteses de modelos cognitivos idealizados na língua adicional a partir de modelos já existentes em língua materna. Tal premissa foi corroborada pelos dados analisados, através dos quais foi possível concluir que as hipóteses elaboradas pelos aprendizes são levantadas através de estratégias de aprendizagem relacionadas ao uso da multimodalidade, testadas pelos mesmos através do processo de mesclagem conceptual e, consequentemente, comprovadas ou reformuladas, desencadeando o aprendizado de inglês como língua adicional.
\end{abstract}

PALAVRAS-CHAVE: Mesclagem conceptual. Multimodalidade. Aquisição incidental de léxico. Inglês como língua adicional. Videogame de RPG.

\section{ABSTRACT}

This text is a review of a $\mathrm{PhD}$ dissertation which aims to analyze lexical knowledge in English as additional language developed through formation and expansion of idealized cognitive models and frames in players' schemata in extensive reading catered by RPG video game. As results, it is presented a proposition of representation of the idealized cognitive models and frames (FAUCONNIER, 1994) developed by the participants during the cognitive processing of the English vocabulary displayed throughout the phase played, as well as

Submetido em: 31/08/2020 - Aceito em: 10/12/2020 - Publicado em: 24/12/2020

${ }^{1}$ Doutora em Letras: Linguística (UERJ). Professora de língua inglesa (FAETEC) 
discussions about the processes that led to their developments, especially learning strategies (OXFORD, 1999; 2017; CARDOSO, 2016) applied by the subjects, conceptual blending (FAUCONNIER, 1997) between idealized cognitive models in the mother tongue and English as an additional language during the game, and the level of contribution of multimodality (KREES; VAN LEEUWEN, 1996; HEMAIS, 2015) in the conceptual blending of these idealized cognitive models. The premise in this research was that the redundancy of information provided by the multimodality present in RPG video games would allow the formulation of hypotheses of idealized cognitive models in the additional language from models already existing in the learner's mother tongue. Such premise was corroborated by the data analyzed, through which it was possible to conclude that the hypotheses elaborated by the apprentices are raised through learning strategies related to the use of multimodality, tested by the learners through the process of conceptual blending and, consequently, proved or reformulated, triggering English as additional language learning.

KEYWORDS: Conceptual blending. Multimodality. Incidental lexical acquisition. English as additional language. RPG video games.

\section{RESUMEN}

Este texto es un resumen de la tesis que tuvo como objetivo analizar el conocimiento léxico en inglés como lengua adicional desarrollado a través de la formación y expansión de modelos cognitivos idealizados y frames en la mente de los jugadores durante la lectura extensa proporcionada por los videojuegos RPG. Como resultado, se presentaron propuestas para representar los modelos cognitivos idealizados y frames (FAUCONNIER, 1994) desarrollados por los participantes durante el procesamiento cognitivo del vocabulario en inglés presentado durante la fase jugada, así como discusiones sobre los procesos que llevaron a su desarrollo, especialmente las estrategias de aprendizaje (OXFORD, 1999; 2017; CARDOSO, 2016) empleadas por los participantes, la mezcla conceptual (FAUCONNIER, 1997) entre modelos cognitivos idealizados en lengua materna y en inglés como lengua adicional durante el juego, y el grado de contribución de multimodalidad (KREES; VAN LEEUWEN, 1996; HEMAIS, 2015) en la mezcla conceptual de estos modelos cognitivos idealizados. La premisa de esta investigación fue que la redundancia de información que brinda la multimodalidad presente en los videojuegos RPG permitiría formular hipótesis de modelos cognitivos idealizados en el lengua adicional a partir de modelos ya existentes en la lengua materna. Esta premisa fue corroborada por los datos analizados, a través de los cuales se pudo concluir que las hipótesis elaboradas por los aprendices se plantean a través de estrategias de aprendizaje relacionadas con el uso de la multimodalidad, probadas por ellos a través del proceso de mezcla conceptual y, en consecuencia, probadas o reformuladas. desencadenando el aprendizaje del inglés como lengua adicional.

PALABRAS CLAVE: Mezcla conceptual. Multimodalidad. Adquisición accidental de léxico. Inglés como lengua adicional. Videojuego RPG.

\section{INÍCIO DE JOGO}

A tese "Aquisição de léxico em inglês como língua adicional através da mesclagem conceptual em videogames de RPG” (LEÃO-JUNQUEIRA, 2019), defendida no Programa de PósGraduação em Letras da UERJ sob a orientação da Prof. Dra. Janaína Cardoso, analisa dados provenientes da introspecção de jogadores de videogame de RPG aprendizes iniciantes de inglês como língua adicional a fim de compreender, à luz da Linguística Cognitiva e, em especial, da teoria da mesclagem conceptual proposta por Fauconnier (1997), como esse 
processamento cognitivo e ancoramento de vocabulário se dá. A Linguística Cognitiva propõe que a organização do conhecimento na mente humana se dá através de modelos cognitivos idealizados (MCIs) que são multimodais e que se inter-relacionam. Dessa forma, procuramos compreender e descrever o processo de formação e expansão desses MCIs na mente do aprendiz ao lidar com o inglês como língua adicional através da proposição de representações gráficas do processo de mesclagem conceptual durante as tentativas de compreensão feitas pelos participantes durante as sessões de jogo registradas. Assim, buscamos compreender a contribuição desses jogos para a expansão do seu vocabulário nessa língua.

Em pesquisas anteriores, já havíamos concluído que a presença da multimodalidade e do feedback positivo nos jogos desse gênero de fato poderiam oferecer grande potencial para a aquisição de léxico em inglês como língua adicional (LEÃO, 2011), e que a multimodalidade presente nos jogos de videogame, e em especial naqueles do gênero RPG de fato dispara o processamento cognitivo dos itens lexicais em inglês como língua adicional desconhecidos pelo jogador, servindo como pistas cognitivas e contribuindo significativamente para a compreensão das informações apresentadas e também para a formação e expansão de MCIs na mente do aprendiz (LEÃO, 2014). A Linguística Cognitiva propõe que a organização do conhecimento na mente humana se dá através de MCIs que são multimodais e que se inter-relacionam. Dessa forma, procuramos compreender e descrever nessa tese o processo de formação desses MCIs em inglês como língua adicional. Para tal, propomos representações gráficas para os processos de mesclagem conceptual feitos pelos participantes em suas tentativas de compreensão durante as sessões de jogo registradas.

A principal pergunta que norteou a pesquisa foi "como os MCIs em inglês como língua adicional do aprendiz se formam e expandem durante o ato de jogar videogames de RPG?" A premissa da qual partimos é a de que a redundância de informações provida pela multimodalidade presente nos jogos de videogame de RPG permitiria a formulação de hipóteses de MCIs em inglês como língua adicional a partir de MCIs em língua materna já existentes na mente do jogador. Essas hipóteses seriam testadas pelo aprendiz através do processo de mesclagem conceptual e, consequentemente, comprovadas ou reformuladas, desencadeando a aquisição de vocabulário em inglês como língua adicional. Assim sendo, era 
nosso objetivo geral compreender como se dá a formação de MCIs em inglês como língua adicional durante a atividade de jogar um jogo de videogame de RPG e, para tal, colocamos como objetivos específicos analisar (1) quais processamentos cognitivos são desencadeados pelo jogo de videogame de RPG; (2) como se dá a mesclagem conceptual entre MCIs ativados pela língua materna e pelo inglês como língua adicional durante o jogo; e (3) se a multimodalidade presente nos jogos de videogame contribuem significativamente para a mesclagem conceptual desses MCIs.

\section{TRAÇANDO UMA ESTRATÉGIA DE JOGO}

No presente trabalho, foi desenvolvida uma pesquisa de caráter descritivo e de ordem qualitativa que se propôs a observar, analisar e delinear a aprendizagem de vocabulário em inglês como língua adicional através dos jogos de videogame de role-playing game (RPG) sob a ótica da teoria dos espaços mentais (FAUCONNIER, 1994), dos multiletramentos (ROJO, 2012; MONTEIRO, 2015), da multimodalidade (KREES; VAN LEEUWEN, 1996; HEMAIS, 2015) e das estratégias de aprendizagem (OXFORD, 1999; 2017; CARDOSO, 2016). Para tal, entendeu-se a linguagem como um construto social, ou seja, não como um sistema abstrato de regras e inerente à fisiologia do cérebro humano, mas sim algo que é desenvolvido através da interação social, performando um papel pragmático ativo no comportamento humano (MALINOWSKI, 1935).

O grupo de participantes da presente pesquisa era composto por cinco indivíduos, de ambos os sexos, residentes da região urbana do Grande Rio e falantes de português como língua materna. A idade dos participantes variava entre 20 e 26 anos à época da geração dos dados. Uma filtragem dentre os indivíduos interessados em participar foi realizada, selecionando-se aqueles que não tivessem jogado o título selecionado para a pesquisa, ou mesmo conhecessem o enredo do jogo, e que não tivessem proficiência na língua adicional abordada, chegando-se a um grupo de cinco participantes. A participação de cada voluntário foi realizada em um único encontro, que teve a duração variando em torno de 2 horas para a realização dos três procedimentos avaliação anterior, sessão de jogo e avaliação posterior. 
A principal fonte de dados da pesquisa aqui desenvolvida foi a introspecção (FÆRCH; KASPER, 1987) realizada pelos participantes durante o engajamento em um jogo de videogame de RPG. Para tal, triangulamos os protocolos verbais que registravam as falas introspectivas durante a feitura da fase do jogo, com entrevistas semiestruturadas e a feitura de testes lexicais, ambos antes e depois da sessão de jogo, de modo a elicitar mais falas introspectivas sobre os processos que levaram os participantes a compreender os itens lexicais até então desconhecidos presentes na fase jogada. A condução da pesquisa se desmembrou em quatro procedimentos, sendo eles uma avaliação inicial, composta de uma entrevista inicial e um pré-teste; a sessão de jogo de videogame; uma avaliação posterior, composta de um pósteste e uma entrevista posterior; e a análise dos dados gerados e elaboração da representação dos MCIs evocados e expandidos pelos participantes.

\section{ENFRENTANDO O CHEFE DO JOGO}

Partindo-se da Teoria dos Espaços mentais e da função pragmática proposta por Fauconnier (1994), compreendemos que uma relação estabelecida entre dois objetos nos permite compreender que a descrição de um objeto 'a' pode ser usada para identificar sua contraparte 'b'. Os dados gerados pela introspecção dos participantes ratificam que os aprendizes de fato aplicam essa função pragmática na tentativa de estabelecer relação de referência entre o MCI em português brasileiro como língua materna já formado e uma hipótese de MCI evocado pelo inglês como língua adicional que é construída a partir das informações multimodais do jogo.

Quando esse processo de estabelecimento de relação tem sucesso, como é visto nos casos 1 e 2 da tese, o aprendiz passa a atribuir ao MCI evocado em inglês como língua adicional as características do MCI evocado pelo português brasileiro como língua materna. No primeiro caso, os participantes tentam compreender os vocábulos shield (escudo) e sword (espada). Ao encontrarem esses objetos, vendo suas imagens e podendo utilizá-los em contexto de luta para, respectivamente, se protegerem e desferirem golpes, os participantes puderam identificar seus significados. Já no segundo caso, os participantes puderam compreender o vocábulo buy (comprar) a partir da dinâmica de uso dessa ação do jogo dentro do contexto de obtenção de 
equipamentos em uma loja através do uso da moeda local. Nesse cenário, as relações entre 'pagar', 'vender', o cenário de um balcão de loja e a disposição de mercadorias em prateleiras levaram os participantes a reconhecer o que Fillmore (1982) chama de Evento Comercial e, dentro dela, a ação de comprar uma mercadoria.

Por outro lado, quando essa tentativa de relação não obtém sucesso, como é visto no caso 3, o aprendiz descarta essa primeira hipótese de associação e busca outros MCIs em português brasileiro como língua materna em sua mente até encontrar aquele com o qual ele consiga estabelecer relação com o MCI em inglês como língua adicional que ele está tentando compreender. Nesse caso, a participante tenta compreender o vocábulo fairy (fada). Em um primeiro momento, ela acredita que sua tradução seria 'fogo', confundindo-o com o vocábulo fire (fogo) devido a uma hipótese de sonoridade criada por ela para fairy similar à língua portuguesa. Porém, ao observar as situações ao longo do jogo em que o vocábulo fairy era utilizado, a participante foi percebendo que elas não condiziam com os contextos em que 'fogo' seria utilizado, descartando essa hipótese de significado. Com cada vez mais situações em que fairy era utilizado, a participante pode então criar uma nova hipótese, em que o seu significado seria 'fada' e então, desta vez, confirma-la.

Em ambos os processos, encontramos a dinâmica de interpretação do discurso indicada por Bernardo (2002), em que a interpretação é resultado de um conjunto de espaços, pragmaticamente elaborado e dinamicamente atualizado conforme o discurso se desenrola e conforme são realizados processos inferenciais. Tais dinâmicas são apresentadas graficamente pela pesquisa, de modo a demonstrar as manipulações de estruturas cognitivas feitas pelos jogadores através do processo de conceptualização da mesclagem conceptual, comprovando nossa premissa de que os participantes da pesquisa estabeleceram tentativas mesclagem conceptual entre os MCIs em português brasileiro como língua materna já existentes em sua mente e os MCIs em inglês como língua adicional apresentados pelo jogo.

Para tal, tendo em vista os quatro cenários da mesclagem conceptual (FAUCONNIER, 1997), proporemos que o espaço de input 1 é preenchido pelo MCI ativado pelo inglês como língua adicional e o espaço de input 2, por sua vez, é preenchido pela hipótese de MCI ativado pelo 
português brasileiro como língua materna. Esses inputs são colocados então em possível relação de referência, através de um espaço genérico que é preenchido de um lado pelas características já ancoradas pelo conhecimento de mundo do falante em português brasileiro como língua materna e por outro pelas informações multimodais apresentadas pelo jogo para o MCI ativado pelo inglês como língua adicional.

Quando esse processo é feito com sucesso, resulta dele um espaço-mescla que ratifica ao aprendiz não apenas que o vocabulário em inglês como língua adicional apresentado pelo jogo corresponde a aquele já adquirido em português brasileiro como língua materna, como também funde esses dois MCIs iniciais, tornando-os um só. Com isto, toda característica que seja identificada posteriormente pelo aprendiz como pertencente àquele vocábulo em qualquer uma das duas línguas será automaticamente integrado também ao vocábulo da outra língua. No entanto, caso essa tentativa de mesclagem não obtenha sucesso, o aprendiz a descarta, compreendendo então que sua hipótese de significado para o item lexical em inglês como língua adicional não estava correta - o que, por si só, já é uma aprendizagem - e parte, na sequência, para a formulação de novas hipóteses, novamente com base nas pistas multimodais fornecidas pelo jogo e outras estratégias de aprendizagem, até que encontre uma correlação que resulte em um processo de mesclagem conceptual que possa ser realizado com sucesso.

Para elaborar tais hipóteses de MCI evocado em inglês como língua adicional, pudemos identificar ainda que os aprendizes fizeram uso de estratégias de aprendizagem, em especial as de compensação através da multimodalidade. As estratégias utilizadas pelos participantes foram identificadas e analisadas a partir de registros de protocolo verbal da introspecção dos participantes durante suas tentativas de estabelecer mesclagem conceptual entre os MCIs em português brasileiro como língua materna e as hipóteses de MCI evocados pelo inglês como língua adicional geradas pela experiência linguística durante o jogo.

Dessa forma, para responder à principal pergunta que norteava a pesquisa, pudemos concluir que a aquisição de vocabulário em inglês como língua adicional durante um jogo de videogame se dá pela mesclagem conceptual entre os MCIs já formados em português brasileiro como língua materna e os MCIs em inglês como língua adicional formados durante o jogo. Esses 
MCIs em inglês como língua adicional são inicialmente gerados através da multimodalidade presente nesse gênero de jogo. Ela apresenta redundâncias da informações ao serem, por um lado, verbalizadas pelo jogo em inglês e, por outro, apresentadas ao jogador de forma não verbal, como imagens, sons e outros elementos do contexto situacional em que o personagem do jogador se encontra durante a interação com os personagens simulados pelo jogo (NPCs do inglês non-player character) e o cenário do jogo. Mais além, a multimodalidade do jogo também apresentou informações que não são diretamente apresentadas pelo texto verbal escrito, aprofundando a compreensão dos participantes sobre os vocábulos ali utilizados. Ademais, a multimodalidade dos jogos de videogame de RPG desencadeou o uso de estratégias de aprendizagem de línguas dos mais diversos tipos, indo desde o uso de pistas não linguísticas a até estratégias sociais de interação entre os jogadores, através de seu personagem, e os NPCs.

Os MCIs em inglês como língua adicional formados pelos participantes a partir das informações multimodais do jogo, inicialmente, eram hipóteses de conceptualização daqueles itens lexicais levantadas pelos jogadores que, em seguida, os comparavam aos MCIs já formados em suas mentes em sua língua materna, o português brasileiro, para confirmar - ou não - a compatibilidade entre eles. Pudemos concluir que a mesclagem se dá, portanto, a partir de um processo de comparação entre os MCIs em língua materna e língua adicional que resulte em confirmação de compatibilidade. Essa confirmação de compatibilidade só foi possível graças à multimodalidade abundante dos jogos de videogame de RPG, que permitia a formação de um espaço genérico que abarcasse a comparação entre ambos os MCIs. Observamos que, a partir do momento em que esses MCIs em português brasileiro como língua materna e inglês como língua adicional passam por esse processo de integração conceptual, eles se tornam um MCI único, que abarca o item lexical em português brasileiro como língua materna e o item lexical em inglês como língua adicional, e a conceptualização comum a ambos. Isso significa que qualquer característica, prototípica ou radial, que se apreenda posteriormente para o vocábulo em qualquer uma dessas duas línguas, valerá automaticamente para a sua contraparte na outra língua.

Uma segunda conclusão que pudemos alcançar é a de que o processo de comparação resultando em não confirmação de relação de contrapartida entre os MCIs em língua materna e língua 


\section{Revista Docência e Cibercultura}

adicional desencadeia novos processamentos cognitivos. Neles, novas tentativas de mesclagem ocorrerão, a partir da formulação de novas hipóteses de conceptualização, até que se encontre um MCI evocado pelo português brasileiro como língua materna que permita uma confirmação de compatibilidade com o que se sabe multimodalmente do MCI evocado pelo inglês como língua adicional até aquele momento e, consequentemente, seja possível a mesclagem entre eles, resultando em aprendizagem do vocábulo em inglês como língua adicional. Assim, pudemos afirmar que a não confirmação de uma hipótese feita pelo aprendiz leva a dois aprendizados sequenciais: em um primeiro momento, o jogador internaliza o que aquele vocábulo em inglês como língua adicional não é e, posteriormente, o que ele de fato é.

Em ambos os cenários de confirmação - que leva à mesclagem conceptual - e de não confirmação - que leva ao descarte de hipótese pelo aprendiz seguido de novas tentativas de mesclagem -, percebemos a importância dos jogos de videogame de RPG possuírem uma narrativa elaborada e fornecerem informações em redundância multimodal. Isto porque todos os MCIs que possuímos e construímos são compostos de elementos multimodais, uma vez que as situações experienciais em que os indivíduos vivenciam não se dão apenas através de textos escritos e definições lexicais, mas sim em conjunto com outras vias de informação como imagens, sons, cheiros e outros que caracterizam tanto os itens lexicais em si quanto os contextos em que são encontrados.

Assim sendo, a premissa pressuposta inicialmente nesta pesquisa pode ser confirmada. Os resultados apresentados confirmaram que a redundância de informações provida pela multimodalidade presente nos jogos de videogame de RPG permite a formulação de hipóteses de MCIs em inglês como língua adicional a partir da comparação dessas informações multimodais com MCIs em português brasileiro como língua materna já existentes na mente do jogador. Essas hipóteses de fato foram testadas pelo aprendiz, como previmos, através do processo de mesclagem conceptual e, consequentemente, comprovadas ou reformuladas, desencadeando a aquisição de vocabulário em inglês como língua adicional.

Os jogos de videogame de RPG provaram-se de grande contribuição para o processo de aprendizagem de línguas adicionais. Por se tratarem de atividades de entretenimento, altamente 
imersivas, com grande riqueza contextual, interacional e narrativa; esses jogos oferecem oportunidades ímpares de uso linguístico, que se encontram no limiar entre a interpretação de papeis e a interação real virtual, levando os seus jogadores a se esquecerem, por diversas vezes, que se tratava de uma atividade simulada de interação social. Nessas imersões tão profundas dos participantes, foi possível recortar diversos momentos da atividade proposta em que eles dialogavam diretamente com os personagens simulados pelo jogo, os NPCs, como se esses fossem pessoas reais e como se os jogadores estivessem inseridos em situações reais de interação. Consequentemente, os participantes utilizaram de estratégias de aprendizagem dos tipos motivacional, afetivo e social, de maneiras bem similares às encontradas, não apenas em atividades de instrução formal em sala de aula, como também em interações cotidianas fora do ambiente escolar.

\section{CENA FINAL DE JOGO}

Após a condução da pesquisa, foi possível afirmar que os videogames de RPG permitem a aquisição de léxico em inglês como língua adicional, ao imergir o jogador em um ambiente rico de interação, testagem de hipóteses e prática, desencadeando o uso de estratégias de aprendizagem por parte desse jogador-aprendiz de língua adicional, que levam a mesclagens conceptuais entre a língua materna do aprendiz e língua adicional em que o jogo se dá. Os jogos desse gênero, por serem tecnologias digitais altamente imersivas, apresentam narrativas extensas, complexas e multimodais. Com isso, os videogames de RPG parecem ser excelentes oportunidades de aprendizagem de língua adicional, que proporcionam um conhecimento profundo, complexo e desenvolvido a partir de práticas linguísticas interacionais e situacionais ricas.

\section{REFERÊNCIAS}

BERNARDO, Sandra Pereira. Foco e ponto de vista na conversa informal: uma abordagem sócio-cognitiva. 2002. Tese (Doutorado em Linguística) - Faculdade de Letras, Universidade Federal do Rio de Janeiro, Rio de Janeiro, 2002. 
CARDOSO, Janaína da Silva. Estratégias de aprendizagem: eficácia e autonomia na compreensão oral. Saarbrücken, Alemanha: Novas Edições Acadêmicas, 2016.

FAUCONNIER, Gilles. Mental spaces. Cambridge: Cambridge University Press, 1994.

FAUCONNIER, Gilles. Mappings in thought and language. Cambridge: Cambridge University Press, 1997.

FÆRCH, Claus.; KASPER, Gabriele (Eds.). Introspection in second language research. Avon, EUA: Multilingual Matters, 1987.

FILLMORE, C. Frame semantics. In: Linguistic Society of Korea (Ed.). Linguistics in the morning calm. Seoul: Hanshin Publishing, 1982. p. 111-137.

HEMAIS, Barbara Jane Wilcox. Práticas pedagógicas no ensino de inglês: integrando gêneros discursivos e multimodalidade. In: HEMAIS, Barbara Jane Wilcox (Org.). Gêneros discursivos e multimodalidade: desafios, reflexões e propostas no ensino de inglês. Campinas, SP: Pontes Editores, 2015, p. 19-34.

KRESS, Gunther.; VAN LEEUWEN, Theo. Reading images: the grammar of visual design. New York: Routledge, 1996.

LEÃO, Luciana Braga Carneiro. The use of RPG video games in English as a foreign language acquisition process. 2011. Monografia (Especialização em Linguística Aplicada ao Ensino/Aprendizagem de Inglês como Língua Estrangeira). - Instituto de Letras, Universidade Federal Fluminense, Niterói, 2011.

LEÃO, Luciana Braga Carneiro. Vídeo games de RPG e a aquisição lexical multimodal de inglês como língua estrangeira. 2014. Dissertação (Mestrado em Estudos de Linguagem) Instituto de Letras, Universidade Federal Fluminense, Niterói, 2014.

LEÃO-JUNQUEIRA, Luciana Braga Carneiro. Aquisição de léxico em inglês como língua adicional através da mesclagem conceptual em videogames de RPG. 2019. Tese

(Doutorado em Letras) - Instituto de Letras, Universidade do Estado do Rio de Janeiro, Rio de Janeiro, 2019.

MALINOWSKY, Bronislaw. Language as tool, document and cultural reality. In: Coral gardens and their magic. v. 2. London, George Allen \& Unwin Ltd., (1935) 1966.

MONTEIRO, Leila Maria Taveira. Multimodalidade na sala de aula de língua inglesa e aquisição lexical. In: HEMAIS, Barbara Jane Wilcox (Org.). Gêneros discursivos e multimodalidade: desafios, reflexões e propostas no ensino de inglês. Campinas, SP: Pontes Editores, 2015, p. 171-189. 
OXFORD, Rebecca L. Anxiety and the language learner: new insights. In: ARNOLD, J. (Ed.). Affect in language learning. Cambridge: Cambridge University Press, 1999, p. 50-67.

OXFORD, Rebecca L. Teaching and researching language learning strategies: selfregulation in context. $2^{\mathrm{a}}$ ed. New York \& London: Routledge, 2017.

ROJO. Roxane Helena Rodrigues. Pedagogia dos Multiletramentos. In: ROJO, R. H. R.; MOURA, E. (Orgs.). Multiletramentos na escola. São Paulo: Parábola Editorial, 2012, p. 1131.

Este é um artigo de acesso aberto distribuído sob os termos da Licença Creative Commons Atribuição Não Comercial-Compartilha Igual (CC BY-NC- 4.0), que permite uso, distribuição e reprodução para fins não comerciais, com a citação dos autores e da fonte original e sob a mesma licença. 